\title{
Investigation of Surface Water Behavior During Glaze Ice Accretion*
}

\author{
R. John Hansman Jr.* and Stephen R. Turnock $\dagger$ \\ Massachusetts Institule of Technology, Cambridge, Massachusetts
}

\begin{abstract}
A series of experimental investigations that focused on isolating the primary factors that control the behavior of unfrozen surface water during glaze ice accretion were conducted. Detailed microvideo observations were made of glaze ice accretions on $2.54 \mathrm{~cm}$ diam cylinders in a closed-loop refrigerated wind tunnel. Distinct zones of surface water behavior were observed; a smooth wet zone in the stagnation region with a uniform water film, a rough zone where surface tension -effects caused coalescence of surface water into stationary beads, and a zone where surface water ran back as rivulets. The location of the transition from the smooth to the-rough zone was found to migrate towards the stagnation point with time. Comparative tests were conducted to study the effect of the substrate thermal and roughness properties on ice accretion. The importance of surface water behavior was evaluated by the addition of a surface tension reducing agent to the icing tunnel water supply, which significantly altered the accreted glaze ice shape. Measurements were made to determine the contact angle behavior of water droplets on ice. A simple multizone modification to current glaze ice accretion models was proposed to include the observed surface roughness behavior.
\end{abstract}

$A$
$C_{i}$
$C_{p}$
$C_{w}$
$D$
$F$
$h$
$k$
$L_{f}$
$L_{s}$
$L_{y}$
$M^{\prime \prime}$
$Q^{\prime \prime}$
$r$
$T_{\text {surf }}$
$T_{\infty}$
$t$
$V_{\infty}$
$W^{\prime}$
$\beta$
$\Delta \theta$
$\Delta T_{\infty}$
$\theta$
$\theta_{a}$
$\theta_{r}$
$\rho_{v, \text { surf }}$
$\rho_{v, \infty}$
$\sigma$

\author{
$=$ surface area, $\mathrm{m}^{2}$ \\ = specific heat capacity of ice, $\mathrm{J} / \mathrm{kg} \mathrm{K}$ \\ = specific heat capacity of air, $\mathrm{J} / \mathrm{kg} \mathrm{K}$ \\ $=$ specific heat capacity of water, $\mathrm{J} / \mathrm{kg} \mathrm{K}$ \\ $=$ diffusion coefficient of water vapor in air, $\mathrm{m}^{2} / \mathrm{s}$ \\ $=$ force, $\mathrm{kg} \mathrm{m} / \mathrm{s}^{2}$ \\ $=$ local convective heat-transfer coefficient, $W / m^{2} K$ \\ $=$ thermal conductivity of air, $\mathrm{W} / \mathrm{m} \mathrm{K}$ \\ $=$ latent heat of fusion of water, $\mathrm{J} / \mathrm{kg}$ \\ $=$ latent heat of sublimation of water, $\mathrm{J} / \mathrm{kg}$ \\ $=$ latent heat of vaporization of water, $\mathrm{J} / \mathrm{kg}$ \\ $=$ local mass flux $/$ time, $\mathrm{kg} / \mathrm{m}^{2} \mathrm{~s}$ \\ $=$ local heat flux $/$ time, $\mathrm{W} / \mathrm{m}^{2}$ \\ $=$ recovery factor, $0.875(-)$ \\ = equilibrium surface temperature, ${ }^{\circ} \mathrm{C}$ \\ $=$ cloud temperature, ${ }^{\circ} \mathrm{C}$ \\ $=$ icing time, $\mathrm{s}$ \\ $=$ freestream velocity, $\mathrm{m} / \mathrm{s}$ \\ $=$ cloud liquid water content, $\mathrm{g} / \mathrm{m}^{3}$ \\ $=$ local collection efficiency $(-)$ \\ $=$ contact angle hysteresis, deg \\ = cloud supercooling $=T_{\infty}\left({ }^{\circ} \mathrm{C}\right)$ \\ $=$ contact angle, deg \\ = advancing contact angle, deg \\ $=$ receding contact angle, deg \\ = saturated vapor density over surface, $\mathrm{kg} / \mathrm{m}^{3}$ \\ $=$ saturated vapor density in cloud, $\mathrm{kg} / \mathrm{m}^{3}$ \\ $=$ surface tension, $\mathrm{kg} / \mathrm{m} \mathrm{s}^{2}$
}

Nomenclature

\section{Introduction}

T HE behavior of unfrozen water on an accreting glaze ice surface can directly and indirectly influence the shape of the resulting ice accretion. The surface transport behavior of the unfrozen water prior to freezing has a direct impact on the ice shape due to its effect of redistributing the impinging water mass. The surface water behavior also indirectly influences the ice accretion through its impact on surface roughness, which modifies the local convective heat transfer. The local heat transfer is the controlling factor in wet surface glaze ice accretion, where there is sufficient impinging water such that ice accretion rate is limited by the ability to remove latent heat of fusion from the surface.

Current ice accretion models ignore the specific details of unfrozen surface water behavior during glaze accretion. The transport behavior and surface roughness are both treated in a simplistic or heuristic manner. This simplistic evaluation of surface roughness and transport behavior, which omits consideration of the surface physics, is considered to be a contributing factor in the poor agreement between current glaze ice accretion models and expeimental results. ${ }^{\prime}$

This paper describes a series of experimental investigations focused on isolating the primary factors that control surface water behavior. The experimental investigations include measurement of the contact angle and resistance to motion of water on an ice surface, photographic observations of surface roughness during glaze ice accretion on cylinders, differential comparisons of substrate thermal and surface properties on ice accretion, and the influence of surface tension on glaze ice accretion. The results indicate the importance of surface water behavior to the icing process in the glaze ice regime. A simple modification to existing glaze ice models is also proposed.

\section{Ice Accretion Mechanisms Influenced by Surface Water Behavior}

The primary ice accretion mechanisms that are influenced by the behavior of unfrozen surface water are the convective heat transfer, which is strongly related to the surface roughness, ${ }^{2}$ and the mass transfer at the surface, which is partly determined by the water runback characteristics of the surface. Both the
†Research Assistant, Aeronautics and Astronautics; currently at The University of Southampton, England.

*J. Aircraft, vol. 26, no. 2, 1989. 
heat and the mass transfer will be discussed briefly in the context of ice accretion models to identify the importance of surface water behavior on the ice accretion process.

\section{Mass Transfer}

The principal modes of liquid water mass transfer on an accreting ice surface are shown schematically in Fig. 1, which depicts mass flux into and out of a control volume at the ice surface. The primary source of liquid water is the impingement of supercooled droplets. The impinging liquid water mass flux $\dot{M}_{\text {imp }}^{\prime \prime}$ is linearly related to the ambient liquid water content $\boldsymbol{W}$, the local droplet collection efficiency $\beta$, and the freestream velocity $V_{\infty}$ :

$$
\dot{M}_{\text {imp }}^{\prime \prime}=\beta W V_{\infty}
$$

The double prime superscript is used to indicate that the quantity is defined per unit area of the icing surface.

Liquid water may also enter the control volume through mass flow along the surface $\left(\dot{M}_{\text {in }}\right.$ in Fig. 1). Liquid water leaves the control volume through freezing at the ice water interface $\dot{M}_{\text {freeze, }}^{\prime \prime}$ and surface flow out of the control volume $\dot{M}_{\text {out }}$. Some mass also leaves the control volume due to evaporation, but this is generally small in the icing problem and will be neglected in the following analysis. The freezing mass flux $\dot{M}_{\text {freeze }}^{\prime \prime}$ is determined by the ability to convect the latent heat resulting from the water ice phase transition away from the surface. This will be discussed more fully in the following section.

In steady state, the mass flux into and out of a control volume with surface area $A$ must balance

$$
A \cdot \dot{M}_{\text {imp }}^{\prime \prime}+\dot{M}_{\text {in }}=A \cdot \dot{M}_{\text {freeze }}^{\prime \prime}+\dot{M}_{\text {out }}
$$

For rime icing conditions at cold temperatures, the convective heat transfer is sufficient to freeze all of the impinging mass flux. In this case. there is no surface flow, and Eq. (2) reduces to

$$
\dot{M}_{\text {imp }}^{\prime \prime}=\dot{M}_{\text {freeze }}^{\prime \prime}
$$

In glaze icing conditions, there is insufficient heat transfer to freeze all of the impinging mass flux. In this case, the surface flow terms in Eq. (2) have to be considered. In current ice accretion models, all unfrozen water is assumed to run back out of the control volume, while unfrozen water from the next upstream element is assumed to flow into the control volume. ${ }^{1}$

The assumption of uniform runback is quite reasonable for icing conditions where a thin water film covers the glaze ice surface. However, recent NASA high-speed photographic studies indicate that other runback mechanisms may exist. ${ }^{3,4}$ In some of the NASA studies, surface water was observed to coalesce into beads that remained stationary on the accreting ice surface. An example is shown in Fig. 2. The liquid beads were often surrounded by regions of otherwise dry ice surface, and no runback was observed. The NASA observations sug-

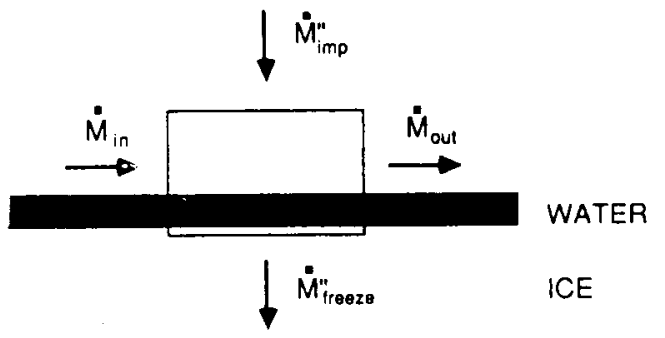

Fig. 1 Control volume mass balance for a wet surface. gest two potential scenarios for surface water flow in the presence of water beads. In one scenario, the water beads will grow until the increased heat transfer from the rough surface becomes sufficient for the freezing mass flux to equal the impinging mass flux and any surface flow into the control volume. In this case, no water would leave the control volume, and Eq. (3) would reduce to

$$
A \cdot \dot{M}_{\mathrm{frecze}}^{\prime \prime}=A \cdot \dot{M}_{\mathrm{imp}}^{\prime \prime}+\dot{M}_{\mathrm{in}}
$$

In the alternate scenario, the water beads would grow through coalescence and impingement until external dynamic pressure and shear forces caused the droplets to slide along or be torn from the surface. In this case, it is unlikely that the drop would move into the next control volume, and the assumption of surface flow continuity implicit in current mass balance models does not hold. This may explain experimental observations of reduced total ice accretion at temperatures near $0^{\circ} \mathrm{C} .{ }^{5}$

It should be noted that both scenarios described above may occur depending on the particular temperature and liquid water conditions. It should also be noted that uniform water films were also observed in the NASA experiments, particularly near the stagnation region.

\section{Heat Transfer}

The thermodynamic analysis presented in this paper for an accreting ice surface follows the earlier work by Olsen et al. ${ }^{\text {s }}$ and others, ${ }^{6.7}$ and is commonly employed in current ice accretion models. ${ }^{1.8}$ The principal modes of energy transfer associated with the icing surface are depicted schematically in Fig. 3. Heat is added to the surface, primarily from the latent heat of

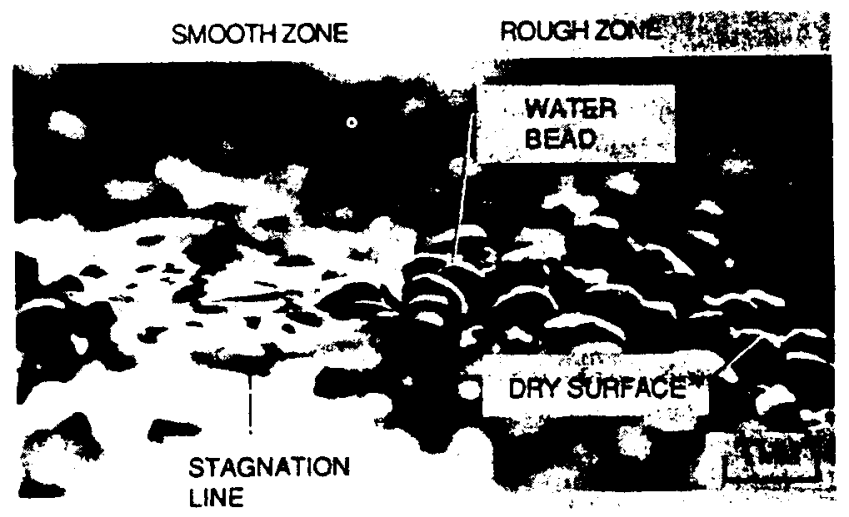

Fig. 2 Grazing angle photograph of a glaze ice surface (courtesy of William Olsen, NASA Lewis Research Center).

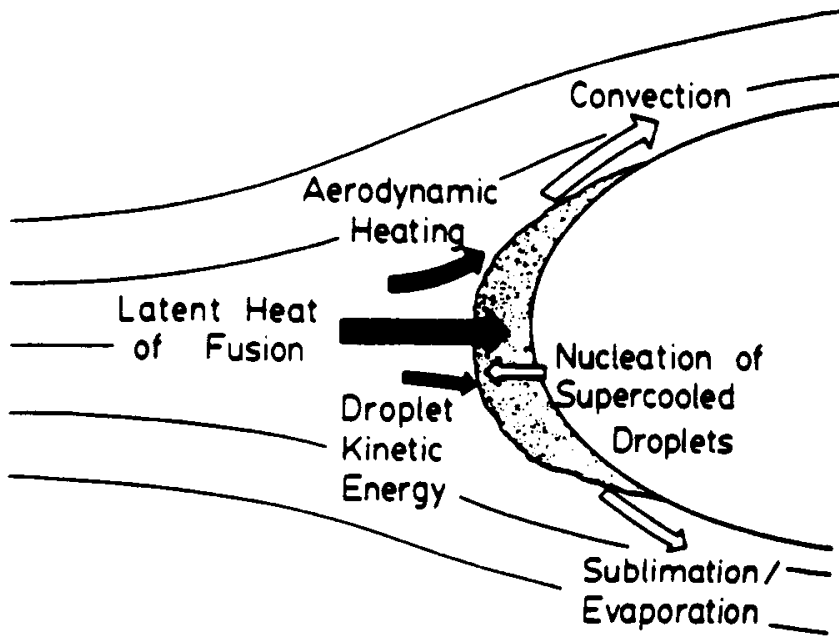

Fig. 3 Modes of energy transfer for an accreting ice surface. 
fusion released as the droplets freeze, but also from aerodynamic heating and, to an even smaller extent. from the kinetic energy of the droplets impacting the surface. Ileat is removed from the surface primarily by convection, and to a lesser degree by sublimation (when the surface is dry) or evaporation (when the surface is wet). In addition, heat is absorbed from the surface as the supercooled droplets impinge and warm to $0^{\circ} \mathrm{C}$.

The assumption of steady state requires that the rate at which energy is added to the control volume equals the rate at which it is removed, i.e.,

$$
Q_{\text {in }}^{\prime \prime}=Q_{\text {out }}^{\prime \prime}
$$

where $Q_{\text {in }}^{\prime \prime}$ and $Q_{\text {out }}^{\prime \prime}$ represent the energy added to and removed from the control volume per unit area per unit time. Equation (2) may be expanded into its component energy terms as

$$
\begin{gathered}
Q_{\text {in }}^{\prime \prime}=Q_{\text {froering }}^{\prime \prime}+Q_{\text {aero heating }}^{\prime \prime}+Q_{\text {droplet kinetic energy }}^{\prime \prime} \\
Q_{\text {out }}^{\prime \prime}=Q_{\text {conv }}^{\prime \prime}+Q_{\text {sub/evap }}^{\prime \prime}+Q_{\text {drop warming }}^{\prime \prime}
\end{gathered}
$$

At steady state it is assumed that the ice surface achieves a locally uniform equilibrium temperature $T_{\text {surf }}$. Conduction into the ice is assumed to be zero, and chordwise conduction between adjacent control volumes is neglected. With these assumptions, the component heat terms of Eqs. (6) and (7) may be written as

$$
\left.\begin{array}{c}
\dot{Q}_{\text {freezing }}^{\prime \prime}=\dot{M}_{\text {freeze }}^{\prime \prime}\left[L_{f}+C_{R}\left(0^{\circ} \mathrm{C}-T_{\text {surf }}\right)\right] \\
Q_{\text {aero heating }}^{\prime \prime}=\frac{r h V_{\infty}^{2}}{2 C_{p}} \\
Q_{\text {droplet kinetic energy }}^{\prime \prime}=\frac{\dot{M}_{\text {imp }}^{\prime \prime} V_{\infty}^{2}}{2}
\end{array}\right\} \dot{Q}_{\text {in }}^{\prime \prime}
$$

Note that both of the primary heat dissipation terms $Q_{\text {conv }}^{\prime \prime}$ and $Q_{\text {evap }}^{\prime \prime}$ contain the local convective heat-transfer coefficient $h$. Also note that the $Q_{\text {freezing }}^{\prime \prime}$ term that dominates the heat flux into the control volume contains the freezing mass flux $\dot{M}_{\text {freeze }}^{\prime \prime}$ This implies that the local ice accretion rate is strongly coupled

Fig. 4 Example of contact angle hysteresis in a droplet on a vertical
wall. to the local convective heat-transfer coefficient. For wet surfaces, the ice accretion rate is essentially limited only by the capability to transfer the latent heat of the freezing water atway from the surface.

The convective heat-transfer coefficient $h$ has been empirically observed to be strongly dependent on the ambient surface roughness. ${ }^{2}$ Current ice accretion models either empirically generate local convective heat-transfer distributions to match natural ice shapes, ${ }^{9}$ or assume a uniform roughness and use integral boundary-layer techniques to derive heat-transfer distributions. ${ }^{10}$ In these cases, the surface roughness is characterized by an equivalent sand-grain roughness, which is adjusted to match experimental ice accretions.

The surface water behavior is a primary factor in the evolution of roughness on an accreting glaze ice surface. The surface roughness determines the heat-transfer behavior, which ultimately determines the ice accretion rate under glaze conditions. Understanding the generation of surface roughness by the microphysical surface water behavior is, therefore, a key component to understanding the glaze ice accretion process.

\section{Microphysies of Surface Water Behavior}

\section{Forces Influencing Surface Water Behavior}

The microphysical behavior of water on an aircraft surface is controlled primarily by the relative strength of the surface tension, and by aerodynamic and body forces. Surface tension forces tend to minimize the surface area of the fluid, causing the water to coalesce into beads or rivulets. They also act to oppose motion of fluid along the surface. Body forces such as gravity or centripetal acceleration act on the entire fluid bulk. Aerodynamic forces result from pressure gradients and shear stress at the water-air interface.

\section{Contact Angle}

An important parameter in surface fluid behavior is the contact angle $\theta$. It is defined as the angle the fluid-vapor interface makes with an underlying substrate. The nominal contact angle is a property of the specific gas-liquid-solid combination, and may vary with temperature. The wettability, or tendency of a fluid to spread on a particular surface, is inversely related to the contact angle $\theta$. In general, for contact angle values of less than $10 \mathrm{deg}$, the surface is considered wettable.

If the fluid is subject to an external force such as gravity, the contact angle may vary, depending on the direction of the force relative to the contact line. This hysteresis effect can be visualized in the schematic view of a drop sliding down a vertical surface, shown in Fig. 4. On the lower surface of the drop the advancing line of contact causes an increase in the contact angle to its maximum allowable value $\theta_{a}$. Conversely, the receding edge of the drop remains at the lowest allowable value of the contact angle $\theta_{r}$. The contact angle hysteresis $\Delta \theta$ is the difference between the advancing and receding contact angles:

$$
\Delta \theta=\theta_{a}-\theta_{r}
$$

The contact angle hysteresis $\Delta \theta$ is a property of the specific gas-liquid-solid combination, and will tend to increase with surface roughness. The resistance to motion of the liquid-solid line of contact can be related to the value of the nominal contact angle and its hysteresis. ${ }^{11}$ In general, increasing values of $\theta$ and $\Delta \theta$ imply increased resistance to motion.

\section{Modes of Surface Water Behavior}

Water on an aircraft surface tends to behave in one of three distinct modes depending on the water flow rate, aerodynamic forces, and the wettability of the surface. For high flow rates and wettable surfaces, the water will tend to coat the entire surface with a uniform film. For lower flow rates, or higher contact angles, there is insufficient water to coat the entire surface. Once drying begins, surface tension forces will tend to 
coalesce the available water into either rivulets or water beads. Water beads are generally associated with low flow rates or unwettable surfaces such as wax. Equation (10) represents the overall force balance for a small stationary water bead. As long as the contact line force is greater than the sum of the aerodynamic and body forces, the bead will remain stationary.

$$
\boldsymbol{F}_{\text {contact }} \geq \boldsymbol{F}_{\text {aero }}+\boldsymbol{F}_{\text {body }}
$$

The contact line force $\boldsymbol{F}_{\text {consac }}$ is the total force resulting from the contact line resistance to motion described in the preceding section. Both the contact line force and the aerudynamic force are roughly proportional to the beads surface ared. whereas the body force is proportional to the bead volume. This implies that, as the bead size is increased, there will be maximum stationary bead volume for a given set of surface, flow, and gravitational conditions above which the bead will move.

\section{Measurement of Contact Angle Between Ice and Water}

As discussed in Sec. III, the contact angle $\theta$ and hysteresis $\Delta \theta$ are important parameters in the behavior of water on an ice surface. There is, however, very little data available on $\theta$ and $\Delta \theta$ for water on ice. This is partly due to experimental difficulties. Most investigations of the surface properties of supercooled water have concentrated on measurements of surface tension $\sigma .^{12}$ In order to obtain preliminary working values of $\theta$ and $\Delta \theta$ for water on ice, a series of simple experiments were conducted.

\section{Experimental Setup}

The apparatus employed in these investigations is shown schematically in Fig. 5. A smooth layer of ice, approximately $8 \mathrm{~mm}$ thick, was formed from distilled water on a metal plate that could be oriented at a variety of angles with respect to the horizontal. Precooled droplets of distilled water were placed on the ice surface by a syringe, and their shapes were recorded by a CCD microvideo camera oriented to view the ice surface at a grazing angle. By use of a dark background and a diffuse light source, a sharp high-contrast image of the droplet at the icewater interface could be obtained. This enabled contact angles to be measured to an accuracy of approximately $\pm 5 \mathrm{deg}$. The ice surface temperature was monitored by an iron-constantan thermocouple mounted in direct contact with the ice surface. The output of the thermocouple was presented on a digital display within the field of view of the video camera. This produced a simultaneous record of contact angle and surface temperature valid to approximately $\pm 1^{\circ} \mathrm{C}$.

Measurement of the contact angle at various tempcritures was obtained by initially cooling the iced metal plate in a cold box, to a temperature below the target measurement temperature. The plate was then removed from the cold box and mounted horizontally within the field of view of the camera. As the plate warmed to the target temperature, droplets were placed on the surface and their shapes were recorded. Although the droplets would begin to freeze shortly after placement, the initial contact angle was preserved in the frozen drop, and any transient effects could be observed in the video record. In this manner, values of the contact angle of water on ice could be obtained for subfreezing temperatures.

The contact angle hysteresis measurements were made utilizing a similar procedure. However, the iced plate was set to an angle of $30 \mathrm{deg}$ with respect to the horizontal. Each droplet's volume was increased by syringe injection until motion began; at this instant the advancing and receding angles and the surface temperature were measured from the video recording. Results

The observed dependence of contact angle $\theta$ and contacl angle hysteresis $\Delta \theta$ with temperature are shown in Figs. 6 and 7. respectively. Because of the low magnitude, it was not possi-

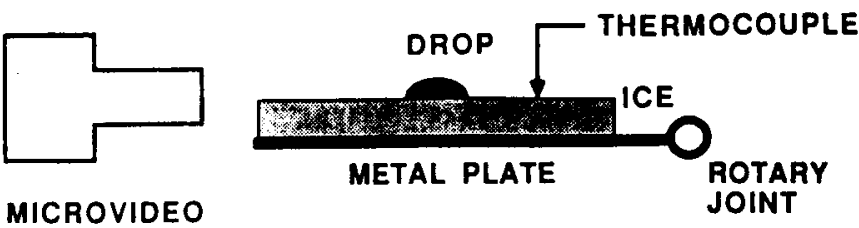

CAMERA

Fig. 5 Schematic of contact angle measurement setup.

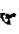

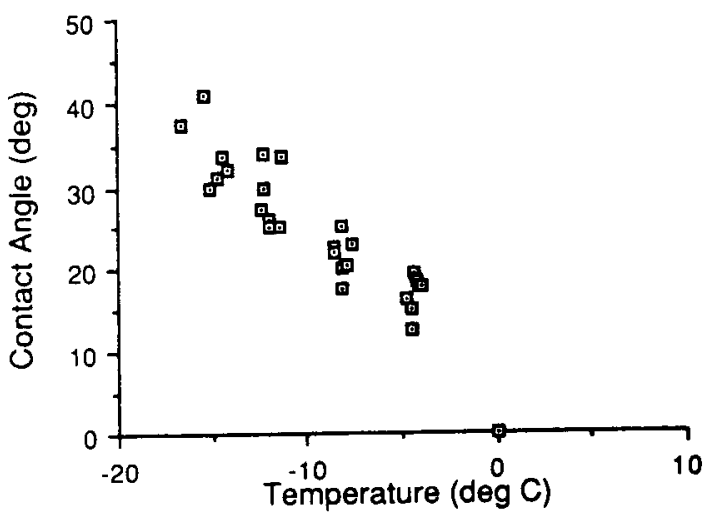

Fig. 6 Contact angle temperature variation for water on ice.

ble to obtain accurate contact angle measurements at temperatures above $-4^{\circ} \mathrm{C}$.

However, at the freezing point $\left(0^{\circ} \mathrm{C}\right)$, ice and water are in equilibrium so that the ice surface must be perfectly wettable, implying that both 0 and $\Delta \theta$ must be zero. These points are included in the contact angle and contact angle hysteresis plots. They are consistent with the experimentally observed values and allow interpolation between $-4^{\circ} \mathrm{C}$ and $0^{\circ} \mathrm{C}$.

Both the contact angle and hysteresis exhibit a strong nonlinear variation with temperature, particularly in the vicinity of the freezing point $\left(0^{\circ} \mathrm{C}\right)$. These results imply that the wettability of the ice surface decreases greatly as the ice surface cools below freezing. For warm ice surfaces (near $0^{\circ} \mathrm{C}$ ) water will tend to spread, and the ice-water contact line will have a low resistance to motion. For colder ice temperatures, water will tend to bead into droplets, which require a higher force to initiate fluid motion.

The strong contact angle temperature dependance indicates the potential importance of thermal gradients to the development of ice surface roughness. Small variations in surface temperature can restrict the mobility of water. This effect is thought to be the cause of the stable nature of the surface water beads observed by Olsen and Walker ${ }^{3.4}$ and shown in Fig. 2. The dry ice surface around the beads can be cooled to temperatures well below $0^{\circ} \mathrm{C}$ by convective heat transfer. This cold dry surface, therefore, imposes a barrier to water flow away from the bead. Any impinging water that strikes the dry surface will quickly be frozen due to the low temperature. Any cloud droplets that strike the water will be trapped within the bead, while glaciation occurs at the lower surface of the bead. In this manner, the ice thickness can increase, while the bead is observed to remain stationary.

\section{Experimental Observations of Ice Surface Roughness on Cylinders}

\section{Experiment Setup}

Detailed photographic observations of the behavior of surface water and formation of ice roughness on cylinders during glaze ice accretion were made in the Data Products of New England Icing Wind Tunnel. The experimental setup is shown 
in Fig. 8. The tunnel was a closed-loop refrigerated system with a 6-in.-square plexiglass test section. The test article was a cylinder that horizontally spanned the test section. Scale reference for the photographic studies was provided by a grid mounted on a thin splitter plate at the midplane of the test section. An $8 \mathrm{~mm}$ CCD microvideo (camera $A$ ) with a macrolens for magnification was used to obtain a grazing angle view of the ice accretion. The camera was focused at the stagnation region near the center of the test section. An additional video camera (camera B) was mounted above and slightly upstream of the cylinder to provide a view of the ice accretion looking normal to the cylinder surface. Secondary lighting was provided to obtain a clear video record of the accreting ice surface.

The tunnel and icing cloud parameters were set to yield a variety of glaze ice conditions. The air velocity was 150 knots for all tests. A range of freestream air temperatures between -9 and $-4^{\circ} \mathrm{C}$ was used. The centerline liquid water content $W$ was varied from 0.7 to $1.2 \mathrm{~g} / \mathrm{m}^{3}$. The icing cloud for the conditions had a nominal mean volumetric diameter (MVD) of $30 \mu$. The standard exposure time was $3 \mathrm{~min}$. The tunnel had previously been calibrated using an indirect method. There is, therefore, some uncertainty in the liquid water content and MVD values.

The liquid water content was observed to vary somewhat across the test section with a reasonably constant valve in the central 2 in. as measured by rime ice accretion calibration runs. Photographic observations were, therefore, focused on the centerline region where the ice deposit was uniform and the liquid water content calibration was valid.

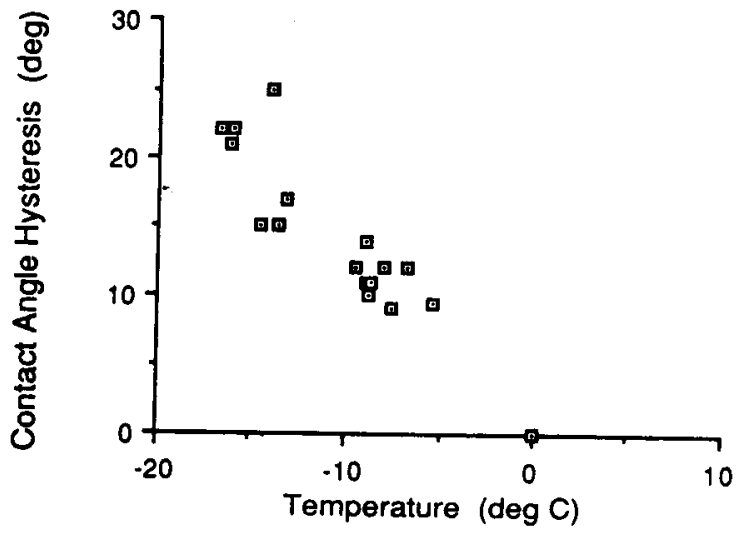

Fig. 7 Contact angle hysteresis temperature variation for water on ice.

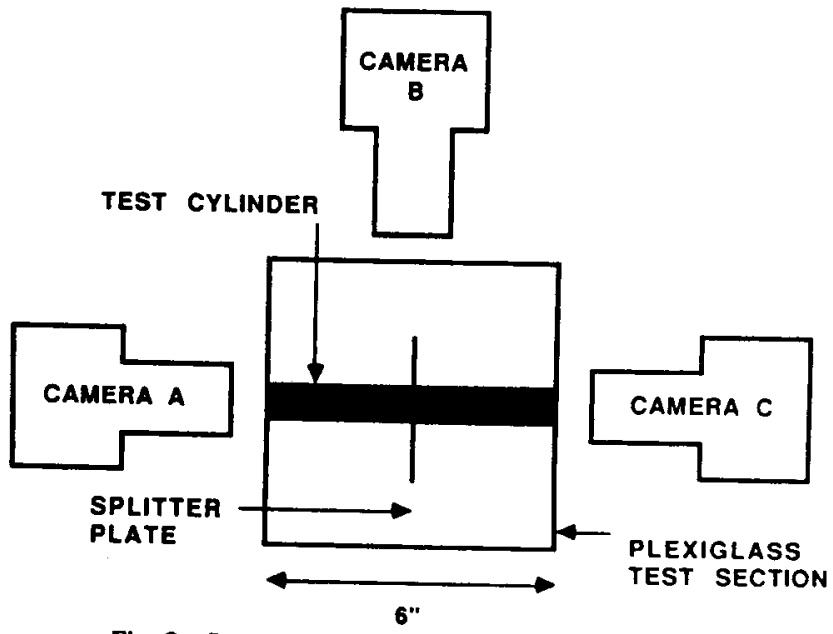

Fig. 8 Schematic cross section of wind-tunnel setup.

\section{Results}

Figure 9 shows a representative final glaze ice shape for an . exposure temperature of $-4.5^{\prime \prime} \mathrm{C}$ and a liquid water contact of $1.0 \mathrm{~g} / \mathrm{m}^{3}$. During the accretion, the following three distinct types of ice surface behavior were observed, each having a characteristic roughness and identifiable boundaries.

1) Smooth Zone. Close to the stagnation point during exposure to the icing cloud, the surface was observed by light reflection techniques to be uniformly wet with a thin film of water at warm temperatures. The surface in this regime was smooth, with no distinct roughness. The ice was translucent within this zone.

2) Rough Zone. At some point downstream, there was a sudden transition to a significantly rougher surface. Within this zone, there appeared to be insufficient water to maintain a uniform film. Surface tension forces dominated the water surface behavior. Runback did not occur; rather, the water tended to coalesce into the water beads first observed by Olsen and Walker. ${ }^{3.4}$ The scale length of the roughness was typically on the order of $1 \mathrm{~mm}$. The transition between the rough and the smooth zones can be clearly seen in the grazing angle photograph shown in Fig. 2.

Inasmuch as there was a distinct boundary between the smooth and rough zones, this position could be easily identified on the grazing angle video recording. The angular position of this boundary is plolled in Fig. 10 for cold $\left(-9^{\circ} \mathrm{C}\right)$ and warm $\left(-4.5^{\prime} \mathrm{C}\right)$ conditions at a liquid water content of $1.0 \mathrm{~g} / \mathrm{m}^{3}$. The boundary started at approximately $50 \mathrm{deg}$ and propagated rapidly towards the stagnation region. The repeatable nature of the smooth-rough transition's propagation toward the stagnation region implies a clear underlying physical mechanism

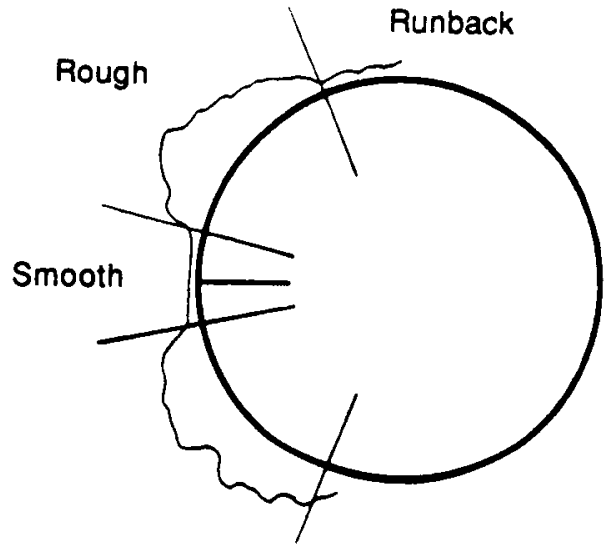

Fig. 9 Typical final glaze ice shape showing distinct roughness zones, $r=-4.5^{\circ} \mathrm{C}, W=1.0 \mathrm{~g} / \mathrm{m}^{3}$.

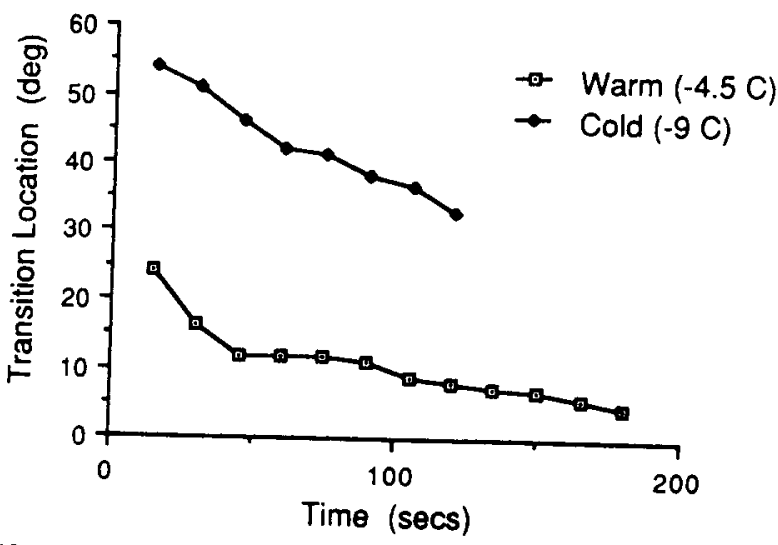

Fig. 10 Angular position vs time of smooth-rough transition location for two air temperatures. 
for the transition between the surface water behavior in the smooth and rough zones.

The ice accretion rate was observed to be enhanced in the rough zone as compared with the smooth zone. This may be seen in the ice profiles of Fig. II taken from the video at 30, 90, and $150 \mathrm{~s}$ after exposure to the icing cloud. The enhanced accretion rate is thought to be due to increased heat transfer resulting from the greater surface roughness in this zone. In all of the cases observed in this study, the ice horns characteristic of glaze ice accretion were found within the rough zone.

3) Runback Zone. At warm temperatures a third zone was observed aft of the rough zone. This region was characterized by areas of ice interspersed with uniced surface. This ice was observed to form during an initial transition period after cloud exposure. The ice was translucent, and quite often frozen rivulets could be discerned. In warm conditions and high liquid water contents, the surface water was observed to initially runback and then stagnate at the point of flow separation. This water then slowly froze as rivulets or as large coalesced water cells. Once ice began to form in the upstream rough zone, no additional surface water was supplied to the runback zone, and the ice surface remained constant.

\section{Observations of the Effect of Substrate Properties on Surface Water Behavior}

Experimental Setup

Two properties of the initial uniced surface that can affect the surface water behavior are 1) thermal characteristics (i.e., conductivity, specific heat capacity), and 2) roughness of the uniced surface. By exposing two test articles (identical except for either their thermal characteristics or initial surface roughness) to the same icing cloud, it was possible to assess the individual importance of each parameter. Comparative tests of this type were carried out in the icing wind-tunnel setup described in Sec. V. For these experiments, the test article was composed of two 3-in.-long, 1 -in.-diam cylinders of different material composition, separated by a splitter plate. As shown in Fig. 8, each half of the test article was viewed by a grazing angle microvideo camera (cameras $\mathrm{A}$ and $\mathrm{C}$ ). A third camera (B) was mounted above and upstream of the article to simultaneously record the differences between the two cylinders.

Two cylinders were used in the thermal comparison experiments: a copper tube with a 1/16-in. wall thickness to investigate fast thermal response, and a solid plexiglass rod to investigate slow thermal response. To remove the possible influence of surface chemistry effects, each cylinder was covered with a single coat of acrylic paint.

For the roughness experiment, two cylinders were used. Both were manufactured from solid aluminum rods. One was extremely smooth with a polished finish obtained using '0000' emery paper. The rough cylinder had a repeatable surface pattern that was produced by knurling the cylinder on a lathe. The knurling process produces a pattern of trapezoidal surface elements. For the cylinder used in these experiments, the elements had a height of $0.8 \mathrm{~mm}$, a width of $1 \mathrm{~mm}$, and a length of $2.7 \mathrm{~mm}$.

Results

\section{Thermal Comparison}

Figure 12 shows a typical comparison of the final ice shapes obtained after $3 \mathrm{~min}$ exposure for the copper tube and the plexiglass rod. This comparison was run at a temperature of $-5.5^{\circ} \mathrm{C}$ and a liquid water content of $0.95 \mathrm{~g} / \mathrm{m}^{3}$. Although there is not a great deal of difference between the final accretions, the glaze ice horns on the copper cylinder were more sharply defined than on the plexiglass, which had a relatively flat front surface and was slightly thicker in the stagnation region. The angular position of the rough-smooth transition boundary is shown as a function of exposure time for these

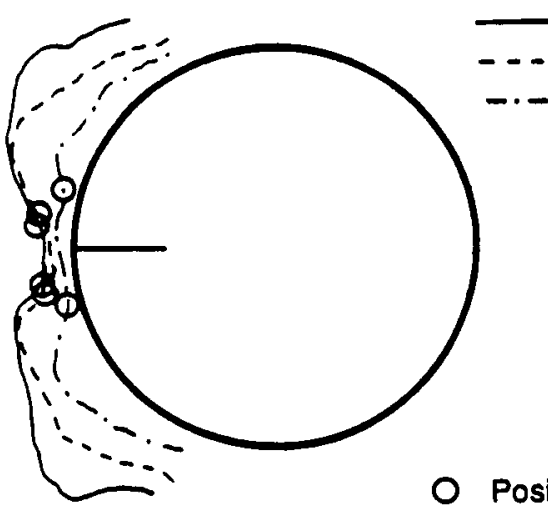

150. Seconds

90 Seconds

30 Seconds $W=1.0 \mathrm{~g} / \mathrm{m}^{3}$.

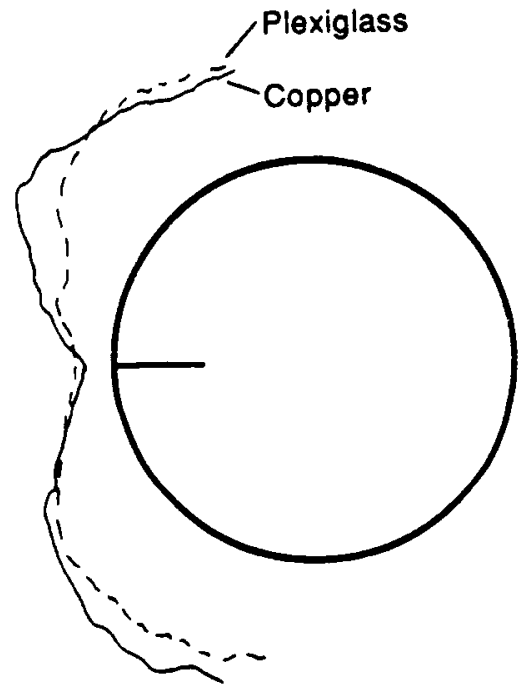

Fig. 12 Typical final ice shape comparison for copper and plexiglass cylinders, $T=-5.5^{\circ} \mathrm{C}, W=0.95 \mathrm{~g} / \mathrm{m}^{3}$.

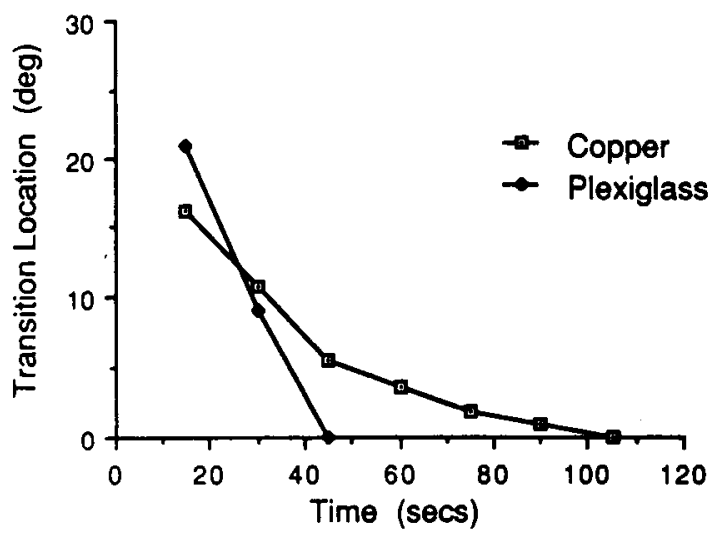

Fig. 13 Angular position of smooth-rough transition vs time for copper and plexiglass cylinders.

accretions in Fig. 13. For the plexiglass cylinder, the smooth zone shrinks much more rapidly than for the copper. The ice surface on the plexiglass cylinder became uniformly rough after $45 \mathrm{~s}$ of exposure. The enhanced roughness in the stagnation region, after this time, accounts for the thicker ice in the stagnation region and the relatively flat front ice surface observed in Fig. 12. 
The water surface behavior after initial exposure to the icing cloud was observed to differ between the copper and plexiglass test articles. For the copper cylinder, there was relatively little surface water flow prior to freezing, and the initial icc surface was relatively smooth. For the plexiglass, droplet coalescence and runback were observed to occur prior to the initial ice formation. This resulted in a significantly rougher initial ice surface, which is thought to be the cause of the difference in accretion behavior observed between the plexiglass and copper test articles.

In general, the differences in ice accretion behavior due to substrate thermal properties were observed to be most significant during the initial phase of ice accretion. As the accretion grows, the effect of initial conditions begins to wash out. After extended icing encounters, the accretion will tend toward a shape that is controlled by the environmental parameters and is independent of substrate properties.

Uniced Surface Roughness

A typical comparison of final ice profiles for the polished (smooth) and knurled (rough) cylinders is shown in Fig. 14. The ice horns on the knurled cylinder were broader and further off the stagnation line than the horns on the polished cylinder. This is thought to be due to enhanced heat transfer in the horn regions during the initial phase of the ice accretion. A slight but repeatable asymmetry was observed in the polished ice growth. This is thought to be duc to the smooth surface on the polished cylinder, which allowed gravitational forces to influence the initial surface mass flux, resulting in a larger ice horn on the lower surface.

The zones of smooth and rough ice growth discussed in Sec. $V$ were observed in both the polished and knurled cases. Figure 15 plots the angular position of the rough-smooth transition vs time. There is some difference between the two cases, with the smooth zone being smaller for the knurled cylinder after approximately 80 s exposure time. An important observation was that the trapezoidal element pattern of the knurled cylinder was clearly apparent in the ice accretion within the rough zone. This implies that the roughness geometry propagates in the ice accretion within the rough zone. In the absence of uniced surface roughness, water beading mechanisms appear to be the source elements for the roughness geometry.

VII. Surface Tension Effects on Ice Accretion

\section{Experimental Setup}

The importance of surface water behavior was further investigated by varying the surface tension of the water and studying the effect on the resulting ice accretion. The water surface tension was varied by the addition of a surfactant (Photoflo 200). which reduced the surface tension by approximately a factor of 2, while leaving its bulk properties (density, freczing temperature) unchanged.

The icing wind-tunnel setup was similar to that discussed in Sec. V. Photoflo was added at a dilution of 1:200 to the icing cloud water supply. Icing tunnel conditions were matched as closely as possible between runs carried out with and without the surfactant added. Because the spray system was not specifically calibrated with Photoflo, some uncertainty exists on liquid water content and MVD values. Based on splitter plate ice accretion, this uncertainty is estimated to be on the order of $5 \%$. Photoflo runs were conducted at a liquid water content of $1 \mathrm{~g} / \mathrm{m}^{3}$ and for temperatures between -9 and $-4 \mathrm{C}$.

Results

Final glaze ice profile comparisons between a normal icing cloud and the Photoflo modified cloud exposures are shown in Fig. 16 for the copper cylinder at $-4.5^{\circ} \mathrm{C}$. The addition of Photoflo resulted in an opaque white ice with a smaller scalc surface roughness and a significantly different profilc. The horns were more pronounced and closer to the stagnation point. At the lower temperatures, the glaze ice horn has be-

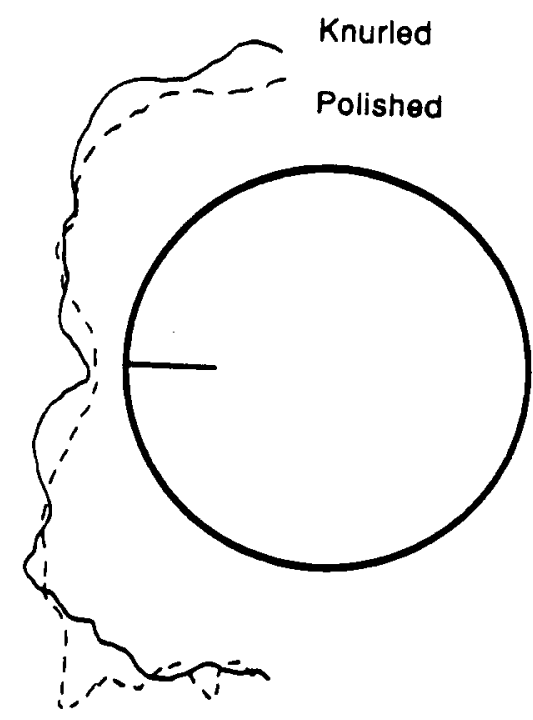

Fig. 14 Typical final ice shape comparison for polished and knurled cylinders, $T=-4.5^{\circ} \mathrm{C}, W=1.0 \mathrm{~g} / \mathrm{m}^{3}$.

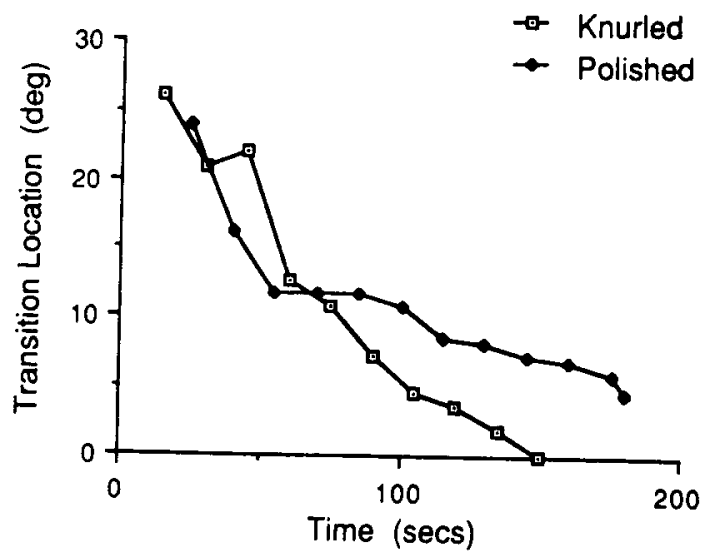

Fig. 15 Angular position of smooth-rough transition vs time for polished and knurled cylinders.

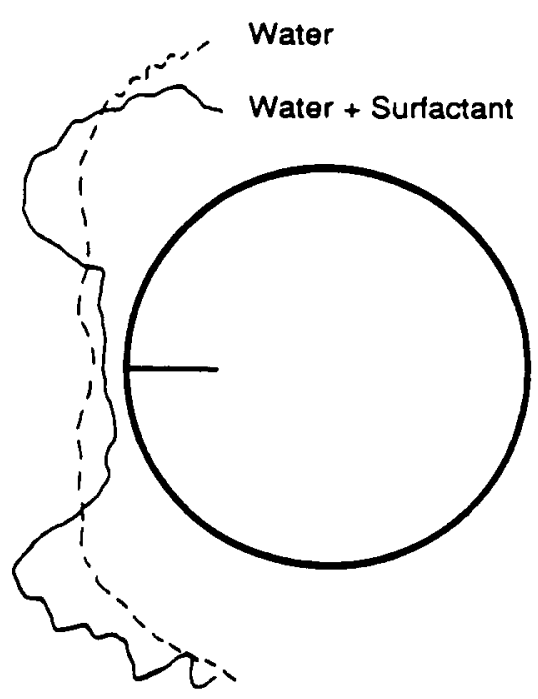

Fig. 16 Typical final ice shape comparison for cloud water supply with and without surfactant, $T=-4.5^{\circ} \mathrm{C}, W=0.95 \mathrm{~g} / \mathrm{m}^{3}$. 
come so pronounced that it no longer collected all of the impinging water. A second horn was, therefore, able to develop behind it.

The different and unusual ice accretions obtained at reduced values of surface tension indicate that surface water behavior is, indeed, an important factor in the glaze ice accretion process and must be considered in physically realistic models.

\section{Implications for Ice Accretion Modeling}

Based on the observations of surface water behavior during glaze ice accretion, a relatively simple modification to the existing ice accretion model is proposed, which may improve the current model's accuracy within the glaze ice regime. In this proposed "multi-zone" model, the accreting ice surface is divided into two or more discrete zones that have varying surface water behavior and surface roughness. This is in contrast to current techniques, which assume that the surface has uniform roughness and surface water runback.

In the simplest version of the model, the surface is divided into two zones. There is a smooth wet zone centered about the stagnation region where thin film runback occurs, and the existing Messinger-type models ${ }^{6}$ appear to be valid. In this region the heat transfer would be that for a smooth surface. The remaining ice surface would consist of a "rough" zone where surface tension effects dominate the surface water behavior, and the characteristic water beads appear. The heat transfer within this region would be adjusted by incorporation of roughness correction factors appropriate to the bead dimensions.

Two primary areas need to be addressed prior to implementation of a two-zone model. They are: 1) determining the smooth-rough transition locations, and 2) determining the appropriate value of equivalent sand-grain roughness to be used in calculating the rough zone heat-transfer coefficient.

The work described in Sec. $V$ indicates that there are distinct physical mechanisms that control the position of the smoothrough transition. However, further work is necessary to parametrically define the location of the smooth-rough transition. In addition, the factors that control the generation of roughness elements within the rough zone need to be investigated in the context of their impact on the local convective heat-transfer coefficient.

\section{Conclusions}

The investigation of surface water behavior on an accreting glaze ice surface has shown the following:

1) Surfaces have been observed to have distinct zones of surface water behavior. They include a smooth wet zone in the stagnation region where uniform film runback occurs, a rough zone where surface tension causes coalescence of the surface water into beads and no runback occurs, and a runback zone where surface water runs back as rivulets.

2) The location of the transition point between the smooth and rough zone was observed to propagate with time toward the stagnation point.

3) The freezing of the coalesced water beads in the rough zone generates a characteristic rough surface that enhances heat transfer.
4) Initial surface roughness patterns were observed to propagate in the accreted ice within the "rough zone."

5) Large variations in ice accretions were observed when the surface tension of the water was changed. This illustrates the importance of surface water behavior.

6) Measurement of contact angle and contact angle hysteresis for water on an ice surface showed a strong variation with the ice surface temperature. This temperature dependence indicates that thermal gradients along the ice surface may be important to surface water behavior and to the generation of roughness on an accreting ice surface.

7) Based on this investigation, a simple muitiple-zone modification to the current glaze ice accretion model is proposed. The model incorporates discrete zones of surface water behavior each with a characteristic surface roughness.

\section{Acknowledgments}

This work was supported in part by NASA and the Federal Aviation Administration under Grants NAG-3-666 and NGL22-009-640. The work was also supported by the National Science Foundation Presidential Young Investigators Program, Award No. 8552702. Use of the icing wind-tunnel facility was provided courtesy of Data Products of New England, and photographic data were provided by Dr. William Olsen of the NASA Lewis Research Center.

\section{References}

'MacArthur. C. D., "Numerical Simulation of Airfoil Ice Accretion," AIAA Paper 83-0112, Jan, 1983.

"Achenbach. E., "The Effect of Surface Roughness on the Heat Transfer from a Circular Cylinder to the Cross Flow of Air," Interna tional Journal of Heat and Mass Transfer, Vol. 20, April 1977, pp. $359-369$

${ }^{3}$ Olsen, W. and Walker, E., "Closeup Motion Pictures of the Icing Process," NASA Lewis Research Center Film, 1983.

${ }^{4}$ Olsen. W. A. and Walker, E., "Experimental Evidence for Modifying the Current Physical Model for Ice Accretion on Aircraft Structures," NASA TM 87184, May 1986.

sOlsen, W., Shaw, R., and Newton, J., "Ice Shapes and the Resulting Drag Increase for a NACA 0012 Airfoil," NASA TM 83556, Jan. 1984.

"Messinger, B. L.. "Equilibrium Temperature of an Unheated Icing Surface as a Function of Airspeed," Journal of the Aeronautical Sciences, Vol. 20, Jan. 1953, pp. 24-42.

'Ludlam, F. H., "The Heat Economy of a Rimed Cylinder," Quarterly Journal of the Royal Meteorological Society, Vol. 77, Oct. 1951, pp. $663-666$.

${ }^{8}$ Macklin, W. C. and Payne, G. S., "A Theoretical Study of the Ice Accretion Process," Quarterly Journal of the Royal Meteorological Society, Vol. 93. April 1967, pp. 195-213.

${ }^{9}$ Gent, R. W. and Cansdale, J. T., "The Development of Mathematical Modeling Techniques for Helicopter Rotor Icing," AIAA Paper 85-0336, Jan. 1985.

${ }^{10}$ Ruff, G. A., "Development of an Analytical Ice Accretion Prediction Method (LEWICE)," Sverdrup Technology Inc., NASA Lewis Research Center Group Progress Report, Feb. 1986.

"Dussan, V. E. B. and Tao-Ping Chow R., "On the Ability of Drops or Bubbles to Stick to Non-horizontal Surfaces of Solids," Journal of Fluid Mechanics, Vol. 137, Jan. 1983, pp. 1-29.

${ }^{12}$ Hobbs, P. V.. Ice Physics, Oxford Univ. Press, London, 1974. 